\title{
The Botrytis cinerea Reg1 Protein, a Putative Transcriptional Regulator, Is Required for Pathogenicity, Conidiogenesis, and the Production of Secondary Metabolites
}

\author{
Caroline B. Michielse, ${ }^{1}$ Matthias Becker, ${ }^{1}$ Jens Heller, ${ }^{1}$ Javier Moraga, ${ }^{2}$ Isidro G. Collado, ${ }^{2}$ and \\ Paul Tudzynski ${ }^{1}$ \\ ${ }^{1}$ Institute of Biology and Biotechnology of Plants, Westfälische Wilhelms-University Münster, Schlossgarten 3, D-48149 \\ Münster, Germany; ${ }^{2}$ Departamento de Quimica Organica, Facultad de Ciencias, Universidad de Cadiz, Puerto Real, Spain
}

Submitted 13 January 2011. Accepted 11 May 2011.

\begin{abstract}
Botrytis cinerea, which causes gray-mold rot, attacks a wide range of plant species. To understand the infection process, the role of a putative transcriptional regulator, BcReg1 (regulator 1), in pathogenicity was studied. This transcriptional regulator shows similarity to the morphological switch regulators Candida albicans Wor1 and Histoplasma capsulatum Ryp1. Gene knock-out and complementation studies revealed that bcreg1 is required for pathogenicity. The bcreg1 mutant is able to penetrate plant tissue but is not able to cause necrotic lesions. In addition, the mutant is blocked in conidia formation and does not produce detectable levels of the sesquiterpene botrydial and the polyketide botcinic acid. Based on transcript expression levels, it can be concluded that bcreg1 is a downstream target of two mitogenactivated protein kinases, BcSak1 and Bmp3.
\end{abstract}

Relationships between plants and fungi are complex and diverse. In many cases, fungi and plants benefit from each other, as in mycorrhizal associations. Conversely, fungi are also important agents of plant diseases; for example, Botrytis cinerea. This fungus causes gray-mold rot or Botrytis blight in over 200 plant species, including most vegetable and fruit crops, shrubs, trees, flowers, and weeds. Due to its wide host range and severe damage to agriculture, efforts have been made to understand the infection process.

Using various molecular approaches, genes involved in pathogenicity have been identified, such as genes whose products play a role in signal transduction, fungal cell wall integrity, plant cell wall degradation, detoxification, appressorium formation, toxin biosynthesis, and generation of an oxidative burst (Choquer et al. 2007; van Kan 2006; Williamson et al. 2007). To identify factors involved in early and late stages of infection, suppression subtractive hybridization, proteome analysis, and macro-array analysis have been performed (Fernandez-Acero et al. 2007; Gioti et al. 2006; Prins et al.

Current address for M. Becker: Institute of Molecular BioSciences, Massey University, Palmerston North, 4442, New Zealand.

Corresponding author: C. B. Michielse;

E-mail: C.B.Michielse@uni-muenster.de

* The $\boldsymbol{e}$-Xtra logo stands for "electronic extra" and indicates that one supplementary figure is published online and that Figures 3 and 4 appear in color online. 2000b; Schulze Gronover et al. 2004; Shah et al. 2009). Until now, only two transcription factors which are involved in pathogenesis have been described: the STE-like transcription factor Ste12, a putative downstream target of the Fus3/Kss1type mitogen-activated protein kinase (MAPK) cascade; and the calcineurin-responsive zinc-finger transcription factor Crz1 (Schamber et al. 2010; Schumacher et al. 2008a).

Recently, a new class of transcriptional regulators involved in morphological switching and pathogenicity has been described (Huang et al. 2006; Michielse et al. 2009; Nguyen and Sil 2008; Srikantha et al. 2006; Zordan et al. 2006). This transcriptional regulator controls the morphological transition: from a filamentous to a yeast form in Histoplasma capsulatum and from a white to opaque cell type in Candida albicans. In both fungi, these different morphological states are correlated with the ability to cause disease. Characterization of $H$. capsulatum Ryp1 and C. albicans Wor1 revealed some common features. For both proteins, it was shown that they are localized in the nucleus and form a self-sustaining positive feedback loop: they bind to their own DNA regulatory region, although the proteins do not contain any known DNA-binding elements, and activate their own transcription. Finally, both proteins control expression of phase-specific genes (Huang et al. 2006; Nguyen and Sil 2008; Srikantha et al. 2006; Zordan et al. 2006). Analysis of the homolog of this transcriptional regulator in the root-pathogen Fusarium oxysporum, Sge1, revealed that this protein is involved in pathogenesis. Although the fosgel deletion mutant was still able to colonize roots of its host plant and to penetrate the root cortex, it was not able to sustain substantial growth within the roots, resulting in a nonpathogenic phenotype. Further analysis showed that the mutant was reduced in conidiogenesis, had an altered metabolic profile, and was unable to express $F$. oxysporum effector genes (Michielse et al. 2009). Although F. oxysporum does not display a morphological switch comparable with $H$. capsulatum or C. albicans (Bishop and Cooper 1983; Lagopodi et al. 2002; Rodriguez-Galvez and Mendgen 1995), it was speculated that FoSge1 might play a role in fungal adaptation during invasive growth (Michielse et al. 2009).

In order to investigate whether the role of this putative transcriptional regulator in pathogenesis is conserved in another nondimorphic plant-pathogenic fungus, this gene, called regulator 1 (bcreg1), was deleted in B. cinerea. We show that the bcregl deletion mutant shares many features with the $F$. oxysporum sgel deletion mutant. In addition, the role of signal 
transduction pathways in regulating bcregl expression was studied and efforts were undertaken to identify putative BcReg1 downstream targets.

\section{RESULTS}

Identification and characterization of $B$. cinerea BcReg1.

In order to identify the $B$. cinerea ortholog of the $F$. oxysporum transcriptional regulator FoSge1, the $B$. cinerea B05.10 genome database was searched using the blastp algorithm and FoSge1 as query. Two proteins, BC1G_11680.1 and BC1G_14615.1, with significant alignments $(E$ value 0.0 and 2.6E-26, respectively) were identified. Phylogenetic analysis revealed that BC1G_11680.1 is the most likely FoSge1 ortholog (Michielse et al. 2009) and this gene was investigated in more detail. The $B C 1 G_{-} 11680.1$ gene, hereafter called bcreg 1 , has an open reading frame (ORF) of 1,521 bp, is not interrupted by introns (verified by reverse-transcription polymerase chain reaction [RT-PCR]) (data not shown), and encodes a protein of 506 amino acids (aa).

The overall amino acid identity of BcReg1 to the known proteins $F$. oxysporum Sge1 (330 aa), H. capsulatum Ryp1 (487 aa), C. albicans Wor1 (785 aa), and Schizosaccharomyces pombe Gti1 (720 aa) is with an identity of $23,30,17$, and $20 \%$, respectively; relatively low. However, as observed earlier (Michielse et al. 2009), the $\mathrm{N}$ terminus of these orthologs, including the BcReg1 protein, is more conserved than the $\mathrm{C}$ terminus. The amino acid identity of the first 120 aa of the BcReg1 protein to the four known analyzed orthologs FoSge1, Ryp1, Wor1, and Gti1 is 45, 50, 34, and 35\%, respectively. An alignment of the first 120 aa revealed the presence of a TOS9 (COG5037) and a Gti1_Pac2 family domain (Pfam09729), which is shared between all orthologs analyzed thus far. In addition, the BcReg1 protein shares a putative protein kinase $\mathrm{A}$ phosphorylation site (KRWTDS/G) and a nuclear localization signal (+107 to +113) with Ryp1 and FoSge1 (Fig. 1), indicating that BcReg1 might be localized in the nucleus as has been shown for FoSge1 and Ryp1 (Michielse et al. 2009; Nguyen and Sil 2008).

\section{Generation of bcreg1 deletion and complementation mutants.}

To assess the role of BcReg1 in pathogenicity, gene knockout and complementation mutants were generated by homologous recombination. Three independent homokaryotic bcregl knock-out mutants were obtained and homologous recombination at the bcregl locus was verified by PCR and Southern analysis. All three mutants behaved the same in subsequent analysis; therefore, one mutant was chosen for complementation with the bcregl locus. One homokaryotic complementation mutant was obtained and, again, homologous recombination at the bcregl locus was verified by PCR (data not shown) and Southern analysis (Supplementary Fig. S1).

\section{BcReg1 is not required \\ for vegetative growth or sclerotia formation but does play a role during conidiogenesis.}

The vegetative growth of the bcregl deletion mutant was assessed on complete and minimal medium and no aberrant growth rate or aerial hyphae formation compared with the wildtype strain was observed (data not shown). However, the deletion mutant developed sclerotia under light conditions in contrast to the wild-type strain. Sclerotia formation in the dark was indistinguishable between the wild type and the deletion mutant (data not shown). The deletion mutant was severely reduced in the formation of macroconidia. Light-microscopic analysis of the deletion strain revealed that the mutant is still able to generate conidiophores; it even seems to produce more conidiophores than the wild-type strain. Using scanning electron microscopy (SEM), we observed that the conidiophores produced by the deletion mutant are more branched compared with the wild-type strain. The deletion mutant is able to form spherical ampulla and denticles at the tip of the conidiophores (Fig. 2) but the denticles do not develop any further into mature conidia. Occasionally, a structure that resembles a mature conidia was observed (Fig. 2); however, germination of these conidia-like-structures was never observed when concentrated "conidial" suspensions were plated onto complete medium (CM), indicating that they are probably nonviable. Microscopic analysis revealed that, in planta, the bcreg1 mutant also develops non-conidia-bearing conidiophores (data not shown). The bcregl deletion mutant is still able to complete its sexual life cycle and form normal apothecia which are indistinguishable from the wild type (J. van Kan, unpublished data). Finally, complementation of the bcregl deletion mutant restores conidiation, indicating that BcReg1 is required for macroconidia formation.

\section{BcReg1 is necessary for pathogenesis.}

Pathogenicity assays on primary leaves of bean plants were performed in order to determine whether the bcregl deletion mutant is affected in pathogenesis. Due to lack of conidia, mycelial plugs were used to inoculate the plants. The bcregl deletion mutant was unable to form necrotic lesions on intact and wounded leaves (Fig. 3A). Even after prolonged incuba-

Fig. 1. BcReg1 contains a conserved protein kinase A phosphorylation site and a nuclear localization signal. An alignment of the first 120 amino acids of Botrytis cinerea BcReg1, Fusarium oxysporum Sge1, Histoplasma capsulatum Ryp1, Candida albicans Wor1, and Schizosaccharomyces pombe Gti1 was created using VectorNTI software. Conserved residues are shaded black and similar residues are shaded gray. The asterisk indicates the conserved threonine residue within the potential protein kinase A phosphorylation site and the predicted nuclear localization signal is boxed. 
tion (7 days after inoculation), necrotic lesions were not observed (data not shown). The deletion mutant did display massive hyphal growth on top of the leaf at the inoculation point. This hyphal growth extended onto the backside of the leaf in case wounded leaves were used in the pathogenicity assay (Fig. 3A). On very rare occasions, the plant cells seem to collapse around the inoculation point in both intact and wounded leaves as the plant cells became transparent (data not shown), possibly
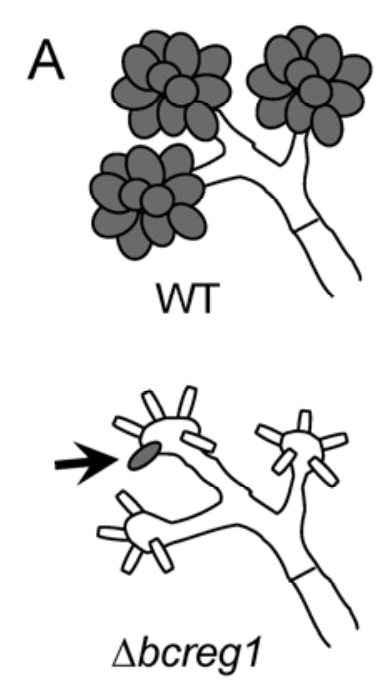
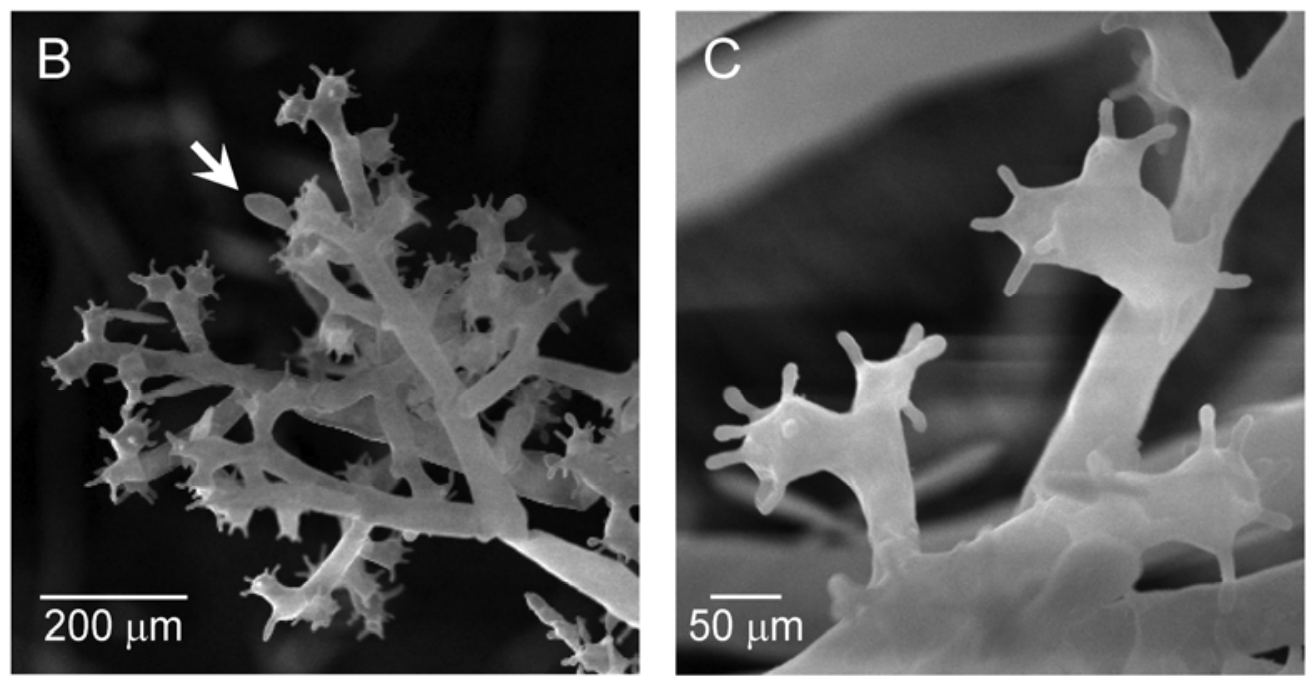

Fig. 2. Deletion of bcregl leads to a conidiogenesis defect. A, Schematic representation of a wild-type (WT) conidiophore (upper panel) and a conidiophore as observed for the bcregl deletion mutant (lower panel). B and $\mathbf{C}$, Conidiophores of the bcreg1 deletion mutant. Mycelial plugs of the bcregl deletion mutant were used to inoculate B5 medium agar plates and, after an incubation of 7 days, scanning electron microscopy recordings were made. Arrow indicates conidia-like-structure.
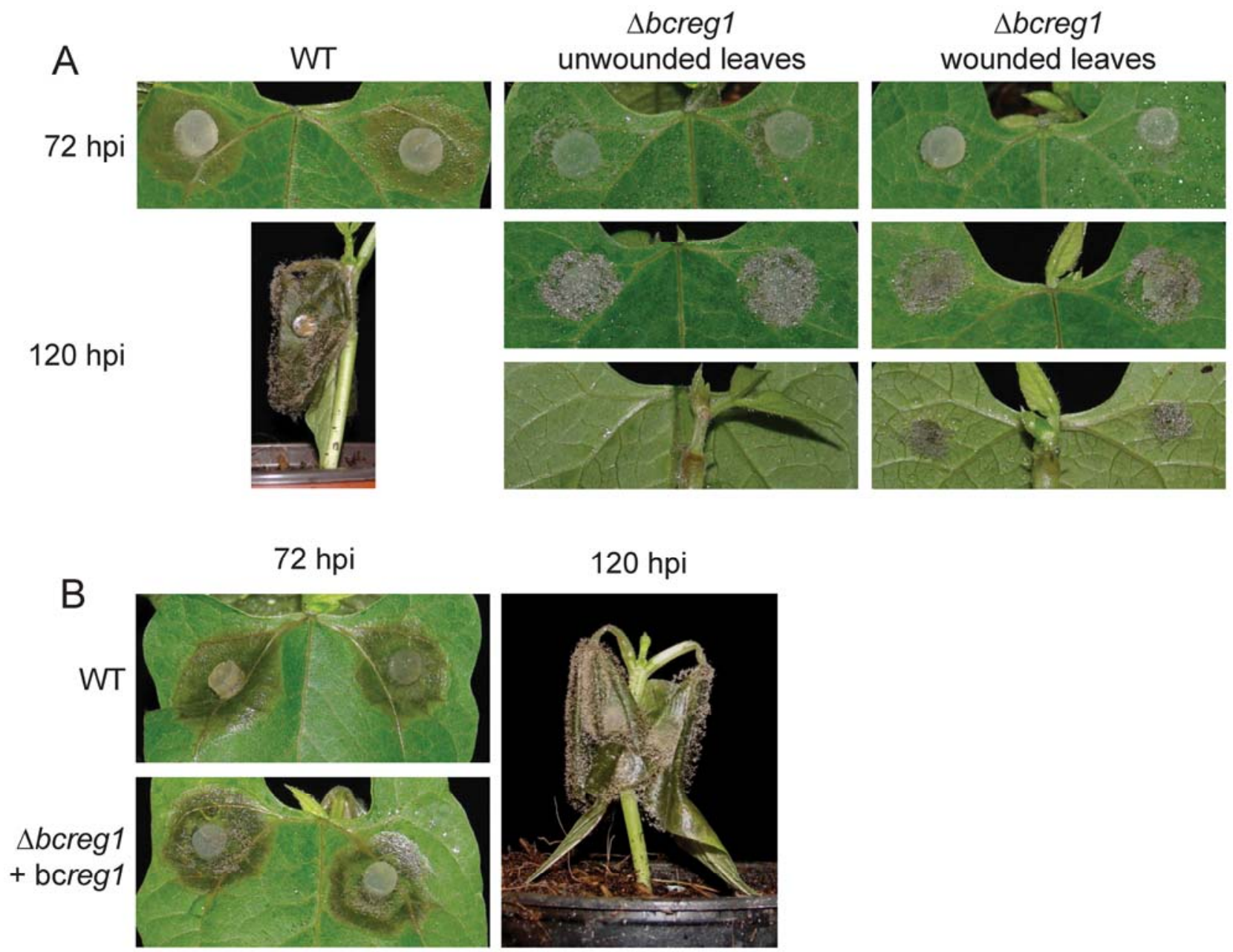

Fig. 3. BcReg1 is required for pathogenicity. A, Pathogenicity assay of the bcregl deletion mutant using bean plants. B, Pathogenicity assay of the bcregl complementation mutant using bean plants. Mycelial plugs of the wild type (WT), the bcregl deletion mutant, and the complementation mutant were used to inoculate primary intact or wounded leaves of bean plants. Disease symptoms were followed in time and pictures were taken 72 and $120 \mathrm{~h}$ postinoculation (hpi). 
due to numerous fungal penetration attempts. Lactophenol Blue staining was used to visualize the hypersensitivity response of the plant cell. This stain is usually excluded from healthy plant cells and penetration of the stain into the plant cell is indicative for membrane damage (Koch and Slusarenko 1990). Again, mycelial plugs were used to inoculate primary leaves of bean plants. At $48 \mathrm{~h}$ postinoculation (hpi) of the wild type and 120 hpi of the bcregl infection of intact and wounded leaves, the leaves were harvested and colorized with Lactophenol Blue. A necrotic lesion can clearly be seen in the wild-type infection at 48 hpi and these damaged plant cells turned blue after staining (Fig. 4). Infection with the bcregl mutant on intact leaves again resulted in massive hyphal growth on top of the leaf but none of the plant cells turned blue after staining (Fig. 4). Wounded leaves infected with the bcregl mutant only displayed a blue coloration of the preinfection-damaged plant cells. Thus, it seems that the bcregl mutant is not able to spread within the leaf and is maintained at the inoculation site. To assess whether the mutant is still able to penetrate the leaf surface, primary bean leaves were again infected with mycelial plugs of the bcregl deletion mutant and, after $24 \mathrm{~h}$ of infection, samples of the inoculation point were taken and analyzed by SEM. Both the wild-type and the deletion strain grew on the plant surface and penetrated the plant tissue (Fig. 5). Complementation of the deletion mutant with the bcregl locus restored pathogenicity using mycelial plugs (Fig. 3B) or spores as inoculants (data not shown). Thus, BcReg1 is not involved in early stages of infection, such as penetration, but is blocked at a later infection stage.

\section{Oxidative stress might influence the growth of the $\Delta$ bcregl mutant.}

During infection, an oxidative burst is generated by B. cinerea and the host itself as a way to facilitate infection and as a defense mechanism against pathogenic attack, respectively (Tudzynski and Kokkelink 2009; van Kan 2006). Therefore, the effect of oxidative $\left(\mathrm{H}_{2} \mathrm{O}_{2}\right)$, osmotic (sorbitol and sodium chloride), and cell wall (Calcofluor White and Congo red) stress on growth of the bcregl deletion mutant was analyzed. The bcregl mutant is not altered in its response to osmotic stress caused by sorbitol or sodium chloride, or by cell wall stress caused by Calcofluor White or Congo red (Fig. 6). However, the mutant is sensitive to oxidative stress caused by $\mathrm{H}_{2} \mathrm{O}_{2}$ compared with the wild type. Addition of 5 or $10 \mathrm{mM} \mathrm{H}_{2} \mathrm{O}_{2}$ to the medium resulted in a significant growth reduction of $35 \%$ $(P<0.01)$ and $68 \%(P<0.001)$, respectively. This growth reduction was only partially restored in the complementation mutant. On CM, in addition to spores like the wild type, the complementation mutant also produces sclerotia under light conditions like the bcregl mutant (data not shown). This indicates a partial complementation of the bcregl vegetative growth phenotype. It could be that the presence of the antibiotic resistance gene disturbs the bcregl locus in such a way that full complementation is not achieved. Based on the abovedescribed plate assay, it can be concluded that BcReg1 is not involved in osmotic and cell wall stress resistance; however, it might be involved in oxidative stress resistance caused by hydrogen peroxide.

\section{Expression of bcreg1 is induced by $\mathrm{H}_{2} \mathrm{O}_{2}$ and bcreg 1 deletion results in reduced expression of several oxidative stress-response genes.}

To investigate the putative role of BcReg1 during oxidative stress in more detail, the expression of bcregl and several known oxidative stress-response genes, two catalases (bccat 2 and bccatC) (Schouten et al. 2002), two glutathione $S$-transferases (bcgstI and bcgstII) (Prins et al. 2000a; Schulze-

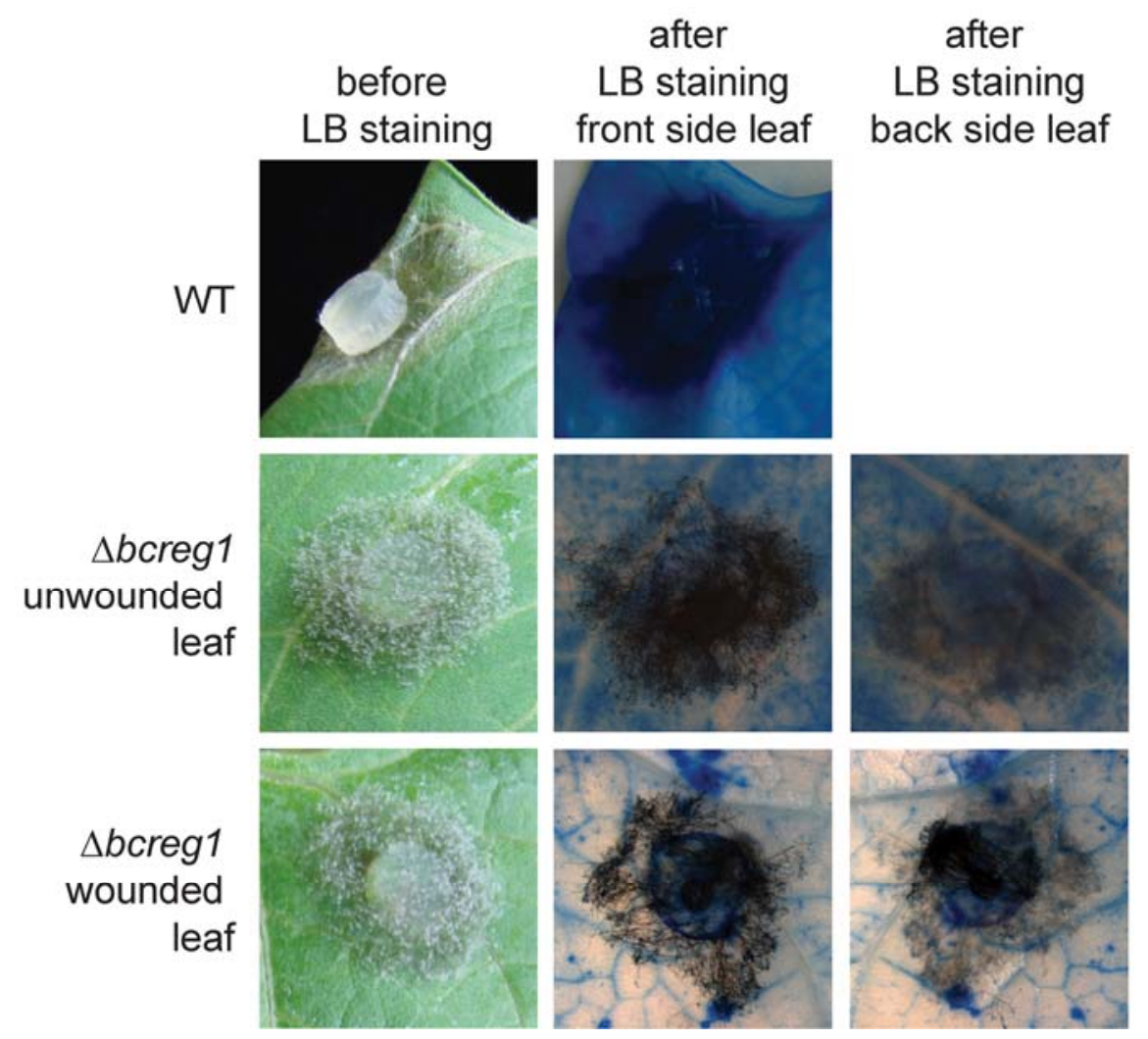

Fig. 4. The bcreg1 deletion mutant does not seem to damage plant cells. Mycelial plugs of the wild type (WT) and the bcreg1 deletion mutant were used to inoculate intact or wounded leaves of bean plants. Leaves were stained with Lactophenol Blue to detect damaged plant cells $48 \mathrm{~h}$ postinoculation (hpi) for the WT infection and 120 hpi of the bcregl deletion mutant infection. The light blue ring visible in leaves infected with the bcregl mutant corresponds to the agar plug used for inoculation. 
Gronover et al. 2004), a glutathione peroxidase (bcgpx), a glutaredoxin (bcgr), and a thioredoxin (bctr) (Temme and Tudzynski 2009) were analyzed in the bcregl deletion mutant under oxidative stress conditions. Addition of $\mathrm{H}_{2} \mathrm{O}_{2}$ to axenic cultures of the wild-type strain resulted in increased expression of bcregl (Fig. 7). Based on quantitative RT-PCR analysis, bcreg1 expression increased 4.5-fold (data not shown). Under oxidative stress conditions, all analyzed oxidative stressresponse genes were upregulated in the wild-type strain (Fig. 7), except for the in planta-induced gene bcgstII (SchulzeGronover et al. 2004), whose expression is $\mathrm{H}_{2} \mathrm{O}_{2}$ independent (Temme and Tudzynski 2009). In the bcregl deletion mutant, the expression of the oxidative stress-responsive genes bcgst I and bccat 2 is severely reduced (Fig. 7). In addition, the expression of bcgstII is reduced under normal and oxidative stress growth conditions (Fig. 7). The expression of the genes coding for glutathione peroxidase, glutaredoxin, thioredoxin, or catalase $\mathrm{C}$ was not significantly reduced in the bcregl mutant. Interestingly, all genes with reduced expression levels in the bcregl mutant are known to be expressed during tomato or bean leaf infection (Prins et al. 2000a; Schouten et al. 2002; Schulze-Gronover et al. 2004), in contrast to the oxidative stress-responsive genes $b c g r, b c g p x$, and bctr, whose expression could not be detected during bean leaf infection (Temme and Tudzynski 2009). Thus, although bcregl expression is increased upon oxidative stress, the deletion only effects the
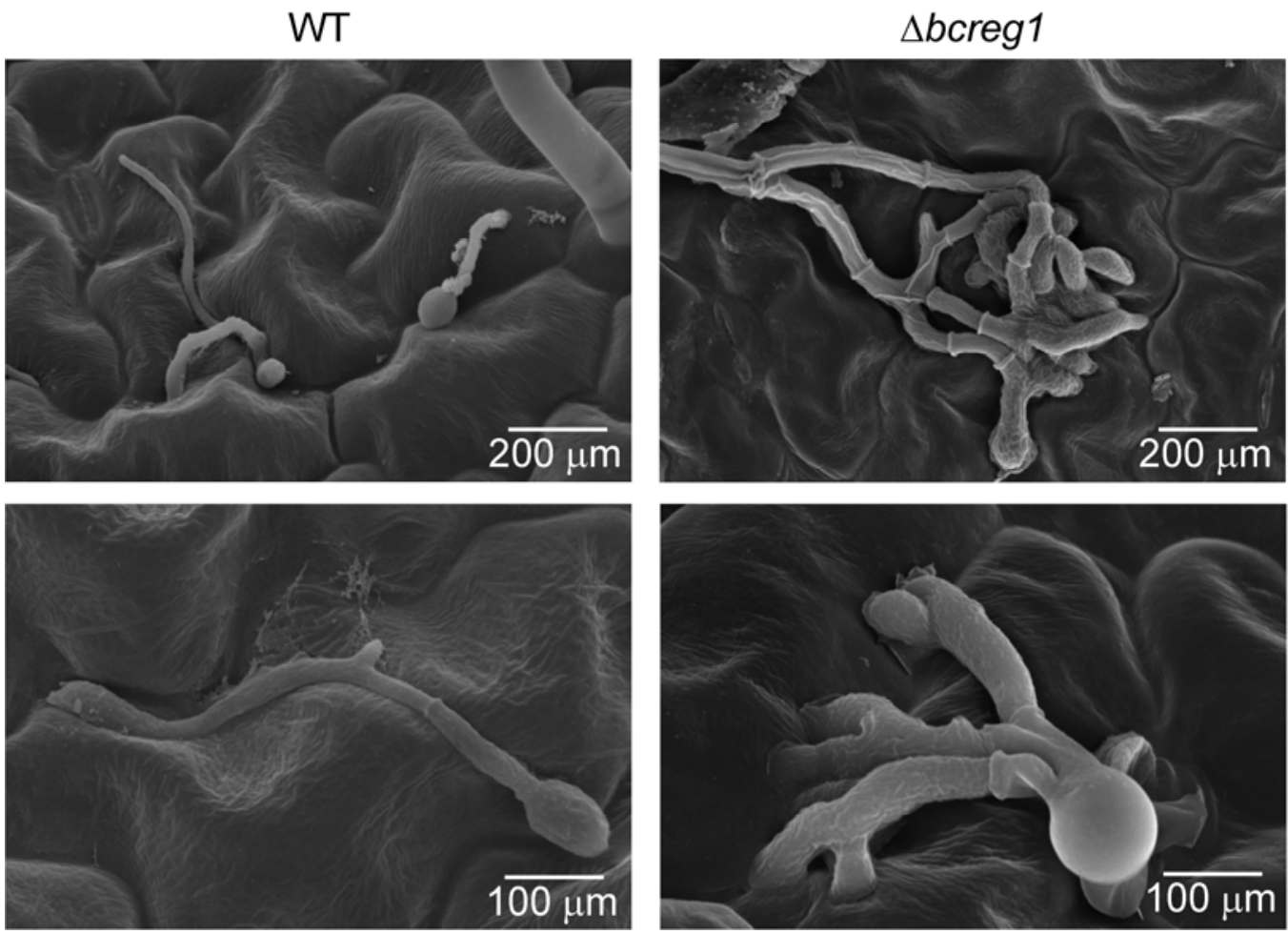

Fig. 5. BcReg1 is not required for penetration. Primary bean plants were inoculated with the wild type (WT) (spores) or the bcreg1 deletion mutant (mycelium plugs) and scanning electron microscopy recordings were made $24 \mathrm{~h}$ postinoculation. The bulbous structure visible in the lower right panel reflects a not-identifiable structure.

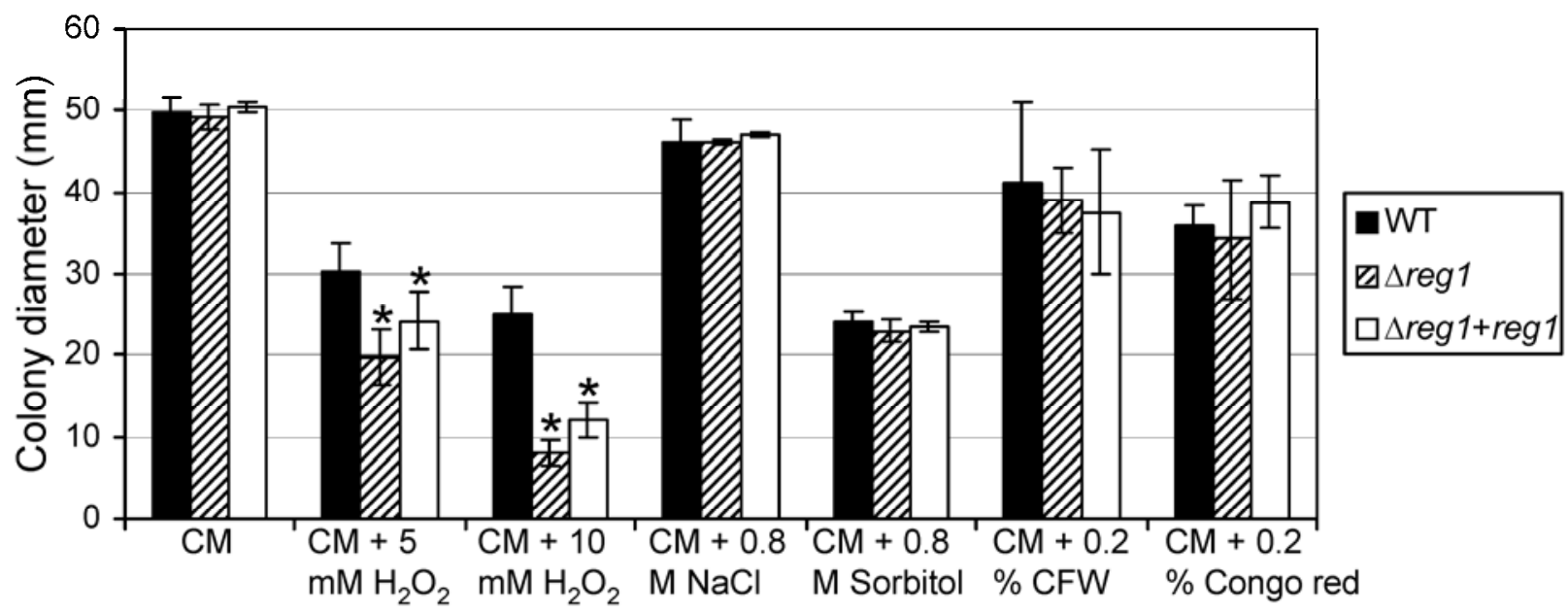

Fig. 6. The bcregl deletion mutant is sensitive to oxidative stress. Mycelial plugs of the wild type (WT), the bcregl deletion mutant, and complementation mutants were used to inoculate complete medium plates supplemented with oxidative, osmotic, or cell wall stress agents, as indicated. Colony diameter was measured after 2 days of incubation. This growth assay was performed in duplo, with two replicates for each condition. A $t$ test was used to determine significant differences; $*$ = significant difference at a $95 \%$ coincidence interval. 
expression of several oxidative stress-responsive genes analyzed. Taken together, the oxidative stress growth assay and the oxidative stress-response genes expression analysis in the bcregl mutant suggest that BcReg1 is important for resistance to oxidative stress but not through the regulation of stress-response genes.

\section{BcReg1 is required for toxin production.}

$B$. cinerea produces phytotoxins, such as botrydial and botcinic acid (Collado et al. 2000, 2007; Reino et al. 2004; Tani et al. 2006), that might facilitate the infection process. Botrydial has been reported to induce chlorosis and seems to facilitate penetration and colonization (Colmenares et al. 2002). However, botrydial has also been shown to be a strain-dependent virulence factor (Siewers et al. 2005). Because the bcregl deletion mutant is unable to cause necrotic lesions during infection, we investigated whether toxin production might be altered in this mutant. Chemical analysis revealed that the bcregl deletion mutant is unable to produce botryane sesquiterpenes and polyketides, such as botrydial, botcinic acid, and botcinin A, whereas the wild-type strain produces these metabolites in various concentrations under the same growth conditions (Table 1). Interestingly, two new metabolites were detected and isolated from mutant extracts. The ${ }^{1} \mathrm{H}-\mathrm{NMR}$ (nuclear magnetic resonance) and ${ }^{13} \mathrm{C}$-NMR spectra indicated a sesquiterpene chemical structure different from those of two sesquiterpene families previously isolated (botryanes and abscissic acid derivatives). Work is in progress to resolve and determine their chemical structures. Thus, the bcregl deletion mutant displays an altered metabolic profile. The production of botryane sesquiterpenes and the polyketides botcinic acid and botcinin $\mathrm{A}$ is completely abolished.

\section{Expression of bcreg1 is dependent of BcSak1 and Bmp3.}

In general, signal transduction pathways, such as the MAPK or the cAMP pathway, mediate adaptation to changing environmental conditions. Components of these pathways have been shown to be involved in, for example, stress response, pathogenesis, and conidiogenesis (Choquer et al. 2007; van Kan 2006; Williamson et al. 2007). To analyze whether ex- pression of bcregl is regulated by these signal cascades, its expression level was determined in MAPK deletion mutants sak1, bmpl, and bmp3 (Doehlemann et al. 2006; Rui and Hahn 2007; Segmüller et al. 2007), and in the deletion mutants of the cAMP-dependent protein kinase encoded by the catalytic subunits bcpkal and bcpka2, the regulatory subunit bcpkaR, and the adenylate cyclase (bac) (Klimpel et al. 2002; Schumacher et al. 2008b). Expression of bcregl was determined under normal and oxidative stress growth conditions. This analysis revealed that bcregl expression is not dependent on the cAMP-pathway or on the MAPK Bmp1 (Fig. 8). However, bcregl expression was severely reduced in the bcsakl mutant. In the bmp3 mutant, expression of bcreg1 under normal growth conditions is similar to expression in the wild type. However, bcregl expression seems to be downregulated during oxidative stress growth conditions. In addition, expression was also slightly reduced in the bac deletion mutant. Thus, bcregl expression seems to be regulated by MAPKs BcSak1 and Bmp3, the homologs of the yeast Hog1 stress response, and the yeast Slt2 cell wall integrity pathways.

\section{DISCUSSION}

In order to establish a successful infection, $B$. cinerea depends on its ability to penetrate, kill, and proliferate in the host tissue. The fungus has developed an arsenal of mechanisms such as enzyme-mediated penetration, toxin and reactive oxygen species (ROS) production, and detoxification mechanisms to establish disease and to overcome host defense reactions (Choquer et al. 2007; van Kan 2006; Williamson et al. 2007).

In this study, we analyzed the role of a putative transcriptional regulator, called BcReg1, which is involved in this pathogenicity process. The bcregl mutant is still able to penetrate its host (bean plants) but is unable to establish disease. The mutant is not affected in vegetative growth but is disturbed in conidiogenesis and is unable to produce the toxins botrydial, its derivatives, and the polyketides botcinic acid and botcinin A. BcReg1 shows homology to the characterized proteins $F$. oxysporum Sge1, H. capsulatum Ryp1, C. albicans Wor1, and Schizosaccharomyces pombe GtiI (Caspari 1997; Huang et al.
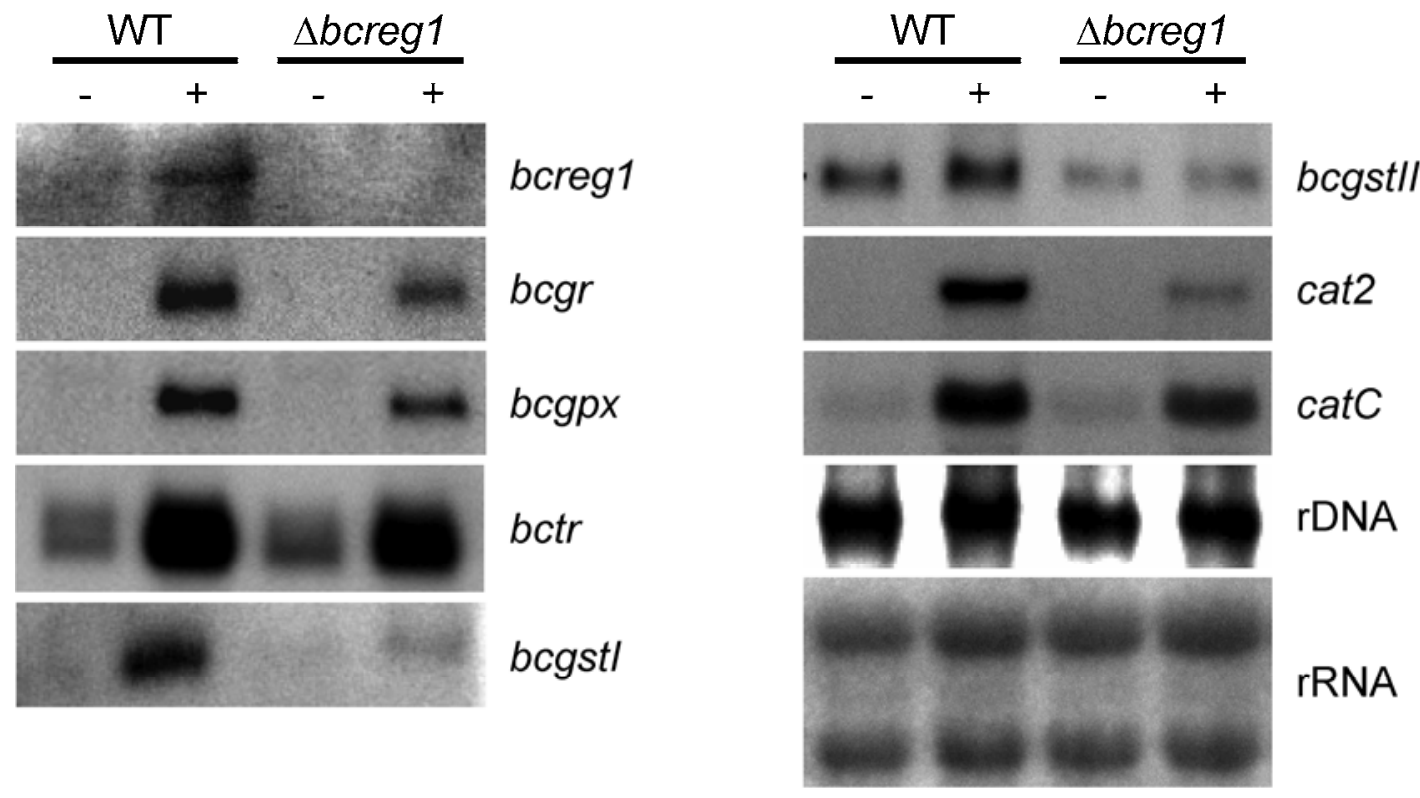

Fig. 7. Expression of oxidative stress response genes in the bcreg1 deletion mutant. Overnight grown liquid mycelial cultures of the wild type (WT) and the bcreg1 mutant were stressed with $10 \mathrm{mM} \mathrm{H}_{2} \mathrm{O}_{2}$ for $30 \mathrm{~min}$, followed by RNA isolation and northern analysis. Polymerase chain reaction products corresponding to bcreg1, catalases bccat 2 and $b c c a t C$, glutathione $S$-transferases $b c g s t I$ and $b c g s t I I$, glutathione peroxidase $b c g p x$, glutaredoxin $b c g r$, and thioredoxin bctr were used as probe. 
2006; Michielse et al. 2009; Nguyen and Sil 2008; Srikantha et al. 2006; Zordan et al. 2006). FoSge1, Ryp1, and Wor1 are nuclear localized proteins and it has been shown that Ryp1 and Wor1 can bind to DNA regulatory regions (Huang et al. 2006; Michielse et al. 2009; Nguyen and Sil 2008; Srikantha et al. 2006; Zordan et al. 2006). Although none of these proteins contain known DNA-binding domains, two conserved boxes, called WOPR box 1 and 2, have been postulated to be required for DNA binding (Lohse et al. 2010). BcReg1 shares a conserved nuclear localization signal with FoSge1 and Ryp1 and contains a WOPR box 1 (amino acids 21 to 104) and a WOPR box 2 (amino acids 160 to 215), suggesting that BcReg1 could be localized in the nucleus and might also contain DNA-binding properties and, thus, could act as a transcriptional activator or repressor.

The pathogenicity phenotypes observed for the fosgel and bcregl mutants show several similarities. In both fungi, these proteins are required to cause disease and for the production of certain secondary metabolites. The penetration ability of these mutants is not impaired but the mutants are blocked in their pathogenicity cycle at a later infection stage (this study) (Michielse et al. 2009). In case of the Botrytis sp. infection, prolonged incubation resulted in massive hyphal growth on top of the leaf at the inoculation site; however, the hyphae did not spread across the leaf, nor was necrosis observed. Staining of the leaves with Lactophenol Blue clearly visualized the damaged plant cells in a wild-type infection; however, no damaged plant cells could be observed in leaves infected with the bcregl mutant. The hypersensitive response (HR), a defense reaction of the plant, has been shown to facilitate $B$. cinerea infection, and it is even proposed that the fungus actively induces programmed cell death or apoptosis to facilitate infection (Govrin and Levine 2000). The bcregl mutant might be disturbed in the secretion of effectors or necrosis-inducing factors, as was shown for the $F$. oxysporum sgel mutant, which is unable to express several virulence and avirulence factors (Michielse et al. 2009). Several proteins and metabolites have been shown to cause cellular death when applied to plant cells or tissues, like the toxins botrydial and oxalic acid, enzymes with endopolygalacturonase and xylanase activity, and Nep1-like proteins (Collado et al. 2007; Kars et al. 2005; Kim et al. 2008; Schouten et al. 2008; van Kan 2006). Analysis of the metabolic profile of the bcregl mutant revealed that the production of botryane sesquiterpenes and the polyketides botcinic acid and botcinin A is completely abolished. Therefore, the absence of necrosis could be due to the absence of necrosis-inducing toxins. The

Table 1. Isolated compounds from the wild type and the bcreg1 deletion mutant ${ }^{\mathrm{a}}$

\begin{tabular}{|c|c|c|c|}
\hline Compound & Chemical formula of the compound & Isolated in wild type (mg/liter) & Isolated in $\Delta$ bcreg1 (mg/liter) \\
\hline 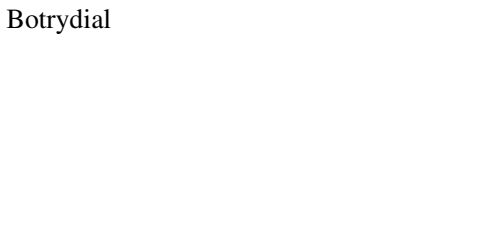 & HH & 3.5 & 更 \\
\hline Dihydrobotrydial & OAc & 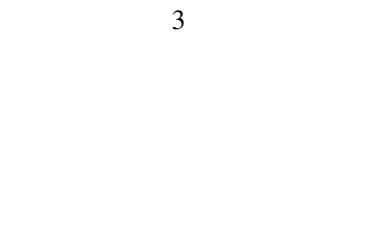 & ND \\
\hline Botryendial & & 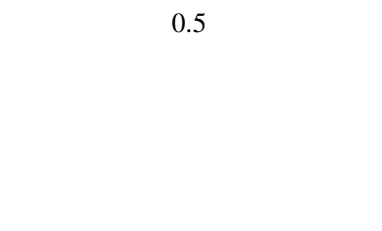 & ND \\
\hline $4 \beta$-Acetoxy-9 $\beta, 10 \beta$-dihydroxyprobotriane & & 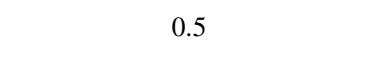 & ND \\
\hline Botcinic acid & & 1.5 & ND \\
\hline Botcinin A & & 2.5 & ND \\
\hline
\end{tabular}

${ }^{\mathrm{a}} \mathrm{ND}=$ not detected 
inability of the bcregl mutant to produce a range of toxins could contribute to its nonpathogenic phenotype. The isolation of a new family of sesquiterpenes from the bcregl mutant broth was intriguing and indicates that, although bcregl is involved in toxin production, the biosynthesis of these new sesquiterpenes is not under control of this gene. Alternatively or in addition to the above-mentioned phenotype, it could be that the bcregl deletion mutant is blocked in its the pathogenicity cycle due to increased sensitivity to host defense reactions. An early defense reaction of the host is the oxidative burst, resulting in the generation of ROS. In addition, B. cinerea also produces ROS itself in planta (Segmuller et al. 2008; Tenberge et al. 2002). Although the sensitivity of bcregl mutant against the oxidative stress agent hydrogen peroxide is inconclusive, the expression of several known hydrogen peroxide detoxification genes is reduced in the bcregl mutant, such as catalase 2 and glutathione $S$-transferase I and II. However, expression of other genes involved in ROS detoxification is not altered in the bcregl mutant. Temme and Tudzynski (2009) found that the Botrytis activator protein 1, a regulator of ROS detoxification, is not essential for virulence and hypothesized that fungal ROS generation might be more important for plant infection than ROS degradation. Therefore, it is unlikely that the absence of detoxification enzymes explains the nonpathogenic phenotype of the bcregl mutant. However, it is still possible that the fungal and plant redox status during interaction between the bcregl mutant and its host is altered, resulting in an incompatible interaction. Less ROS might be produced either by the plant or the fungus. Because ROS is a key component of HR, it could be that, due to less ROS production, HR is not triggered, explaining the absence of necrosis during bcregl mutant infection and a block in host colonization.

How BcReg1 is involved in the regulation of expression of the toxin clusters and other downstream targets is not known at the moment. It could be that the protein binds directly at the regulatory sequences of these genes or that it influences the expression indirectly. A 14-nucleotide-pair motif (WVHWDW TARRSTTT) has been described for C. albicans as the Wor1 recognition sequence (Lohse et al. 2010); however, whether this recognition motif is conserved for the Worl orthologs, including BcReg1, is not known. In the regulatory sequences (upstream region until the next ORF) of bcreg 1 , bcgstI, bcgstII, and cat2, no motif with a $100 \%$ match to the published Wor1 14nucleotide-pair motif could be identified (data not shown).

Another striking overlap in the deletion phenotype between bcregl, $H$. capsulatum ryp 1 , and $F$. oxysporum sgel is the altered conidiogenesis. The rypl mutant produced conidia under nonconidia-producing growth conditions and the fosgel mutant produced sixfold less microconidia (Michielse et al. 2009; Nguyen and Sil 2008). The bcregl mutant is completely unable to produce any mature macroconidia. This indicates that BcReg1 and its orthologs are involved in developmental processes such as the asexual cycle. BcReg1 could possibly directly or indirectly regulate the expression of genes involved in conidiogenesis. Unfortunately, the regulatory pathway controlling sporulation in B. cinerea is not known. However, no differences in expression of genes known to be involved in sporulation in other fungi (e.g. fluG, stuA, and rco-1) (Adams et al. 1992, 1998; Clutterbuck 1969; Yamashiro et al. 1996) between the wild-type and the bcregl mutant were observed (data not shown).

In this study, we show that bcregl expression is regulated by two different MAPKs: BcSak1 and Bmp3. To our knowledge, bcregl is the first identified $B$. cinerea target gene whose expression is controlled by both MAPKs. Cross-talk between these pathways is not uncommon, as has been described for Saccharomyces cerevisiae and C. albicans (Eisman et al. 2006; O'Rourke and Herskowitz 1998). The bcsakl deletion phenotype resembles that of bcregl in many aspects but is always slightly more severe (e.g., lack of penetration ability during infection, lack of conidiophore development, and higher sensitivity to oxidative and osmotic stress response) (Segmüller et al. 2007), indicative that BcSak1 is upstream of BcReg1, as verified by expression analysis. Bmp3 is also required for pathogenicity and conidiation; however, Bmp3 is also involved in vegetative growth and sclerotia formation (Rui and Hahn 2007), indicating that, in addition to the loss of bcregl, other unknown downstream targets contribute to the bmp3 deletion phenotype. In addition, the expression of bcregl seems to be reduced in the adenylate cyclase mutant $(b a c)$, indicating that cAMP levels could be important for bcregl expression. Interestingly, all BcReg1 orthologs contain a conserved protein kinase A (PKA) phosphorylation site. The $F$. oxysporum Sge 1 protein containing a mutation in this phosphorylation site was unable to complement the $F$. oxysporum pathogenicity phenotype, indicating that phosphorylation of FoSge1 is necessary for pathogenicity (Michielse et al. 2009). In addition, the Hog1 and the cAMP pathway have been implicated to play a role in phosphorylation and activation of the BcReg1 orthologs, GtiI+ and Wor1 (Caspari 1997; Huang et al. 2010; Lohse et al. 2010). Although bcregl expression levels were unaltered in the various $p k a$ mutants analyzed, the functionality of the BcReg1

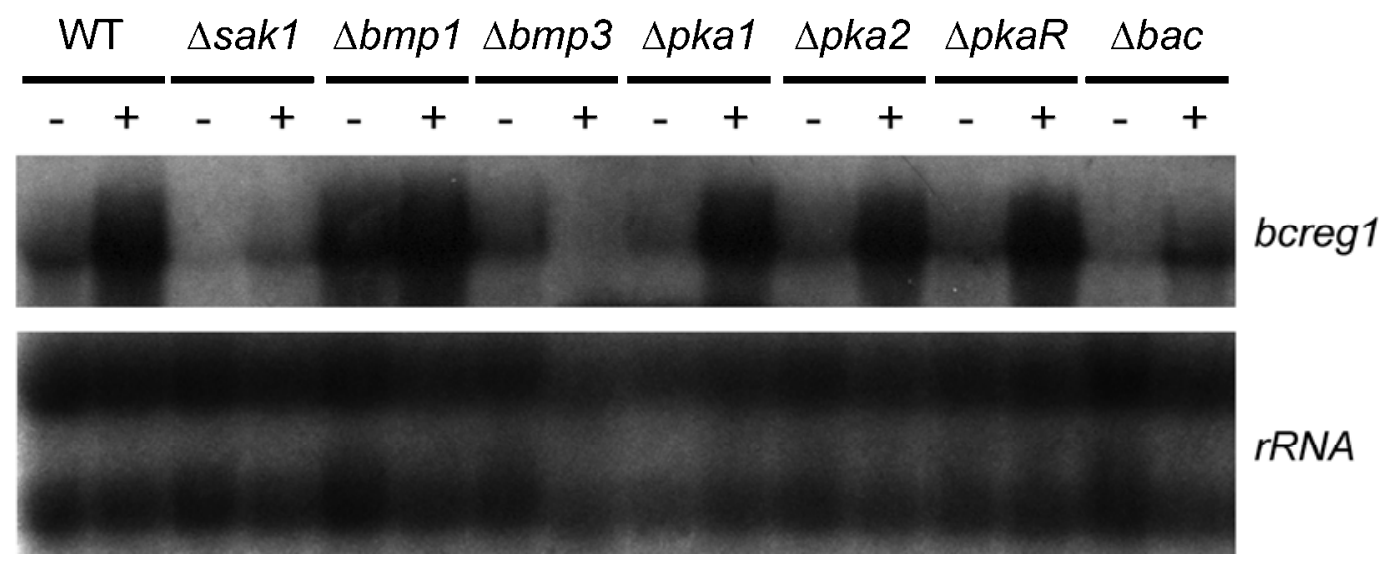

Fig. 8. Bcregl expression is dependent on the mitogen-activated protein kinases (MAPKs) bcsak1 and bmp3. Overnight-grown liquid mycelial cultures of the various mutants (MAPK mutants $s a k 1, b m p 1$, and bmp3 and cAMP pathway mutants pka1, pka2, pkaR, and bac) were stressed with 10 mM $\mathrm{H}_{2} \mathrm{O}_{2}$ for 30 min, followed by RNA isolation and Northern analysis. Symbols: $+=10 \mathrm{mM} \mathrm{H}_{2} \mathrm{O}_{2}$ added and $-=$ no $\mathrm{H}_{2} \mathrm{O}_{2}$ added. A polymerase chain reaction product corresponding to the bcregl open reading frame was used as probe. 
protein in these mutants might be disturbed. The role of the cAMP/PKA pathway on phosphorylation and activation of BcReg1 remains to be elucidated.

In summary, it can be concluded that in the necrotrophic plant pathogen $B$. cinerea $\mathrm{BcReg} 1$, a putative transcriptional regulator, is necessary for conidiogenesis, pathogenesis, and secondary metabolite production. Additionally, insight into the regulation of this gene was obtained; it can be concluded that, in $B$. cinerea, the expression of this gene is regulated by the BcSak1 and Bmp3 MAPK pathways. The role of the MAPK or cAMP pathways in phosphorylation of BcReg1 and whether phosphorylation is necessary for its activity remains to be elucidated, as well as the putative BcReg1 DNA-binding property, its target sequence, and downstream targets.

\section{MATERIALS AND METHODS}

\section{Strains, media, and culture conditions.}

B. cinerea Pers. (teleomorph Botryotinia fuckeliana (de Bary) Whetzel B05.10 (Quidde et al. 1999) was used as a recipient strain for gene replacement experiments. The various Botrytis cinerea strains used in this study (Table 2) were grown on either CM (Pontecorvo et al. 1953), potato dextrose agar (PDA) (Sigma-Aldrich Chemie, Steinheim, Germany) supplemented with 10\% homogenized French bean (Phaseolus vulgaris) leaves, or Gamborg's B5 medium (Duchefa Biochemie BV, Haarlem, The Netherlands) supplemented with $2 \%$ glucose and $1.5 \%$ agar (AppliChem, GmbH, Darmstadt, Germany) at $18^{\circ} \mathrm{C}$ under light conditions.

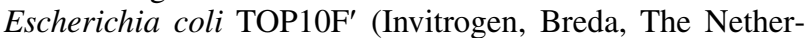
lands) was used for construction, propagation, and amplification of the plasmids and was grown in Luria broth medium (Sambrook and Russel 2001) at $37^{\circ} \mathrm{C}$ containing ampicillin at $80 \mu \mathrm{g} / \mathrm{ml}$.

\section{Construction of bcreg1 deletion and complementation vector.}

Based on the B. cinerea genome sequence, where the bcregl gene corresponds to $B C 1 G_{-} 11680.1$, various primers were developed to generate the bcregl deletion and complementation vector. To generate the bcregl gene disruption construct, a 958-bp upstream fragment and 653-bp downstream fragment were amplified from genomic DNA by PCR with the primer pairs FP1883/FP1884 and FP1885/FP1886, respectively (Table 3). The PCR products were cloned into pGEM-T Easy (Promega, Leiden, The Netherlands) and, subsequently, the XhoI/SalI upstream and the XbaI/NotI downstream fragment were sequentially cloned in pNR1 (Malonek et al. 2004), resulting in pNR1reg1KO. The bcregl complementation construct, pHPreg1COM, was generated in a two-step approach. First, a 3,195-bp Not I/EcoRI fragment containing the bcreg 1 ORF, including 985-bp upstream and 692-bp downstream sequences, was generated by PCR with the primers FP1887 and FP1888 (Table 3) and cloned into pGEM-T Easy, resulting in

Table 2. Botrytis cinerea strains used in this study

\begin{tabular}{|c|c|c|}
\hline Strain & Parental strain & Reference \\
\hline B05.10 & Haploid derivative of SAS56 & Quidde et al. 1999 \\
\hline$\Delta r e g 1$ & B05.10 & This study \\
\hline$\Delta r e g l+r e g l$ & $\Delta$ bcregl & This study \\
\hline$\Delta b c s a k 1$ & B05.10 & Segmüller et al. 2007 \\
\hline$\Delta b m p 1$ & B05.10 & Doehlemann et al. 2006 \\
\hline$\Delta b m p 3$ & B05.10 & Rui and Hahn, 2007 \\
\hline$\Delta b c p k a 1$ & B05.10 & Schumacher et al. $2008 \mathrm{~b}$ \\
\hline$\Delta b c p k a 2$ & B05.10 & Schumacher et al. $2008 \mathrm{~b}$ \\
\hline$\Delta b c p k a R$ & B05.10 & Schumacher et al. $2008 \mathrm{~b}$ \\
\hline$\Delta b a c$ & B05.10 & Klimpel et al. 2002 \\
\hline
\end{tabular}

pGEMreg1COM. The bcregl complementation insert was sequenced on an ABI PRISM genetic analyzer using ABI PRISM BigDye Terminator kit (Applied Biosystems, Nieuwekerk a/d IJssel, The Netherlands), using primers FP1884, FP1885, FP1887, FP1888, FP1905, FP1906, and FP1907 for sequencing (Table 3). The NotI/EcoRI complementation bcreg 1 fragment was subsequently transferred from pGEMreg1COM into pOliHP (Rolke et al. 2004), resulting in pHPreg1COM.

\section{Fungal transformation.}

Protoplast formation and transformation was performed based the procedure as described by ten Have and associates (1998) with adjustments as described by Schulze-Gronover and associates (2001). For bcregl gene replacement, $10 \mu \mathrm{g}$ of an XhoI/NotI pNRreg1KO fragment corresponding to the nourseothricin resistance cassette flanked by up- and downstream sequences of regl was added to B05.10 protoplasts. Homologous recombination was verified by PCR using the following primer combinations: i) FP1941/Tub-T for detection of homologous recombination on the promoter flank, ii) FP1939/FP1940 for detection of the ORF, and iii) pOLIF1/FP1942 for detection of homologous recombination on the terminator flank (Table 3).

For bcregl complementation, $10 \mu \mathrm{g}$ of a NotI/SalI pHPreg1COM fragment corresponding to the hygromycin resistance cassette and the bcregl ORF, including up- and downstream sequences, was added to protoplasts of a bcregl deletion mutant. Integration at the bcregl locus was verified by PCR using the primers FP1939/FP1940 for the detection of the bcregl ORF and Tub-T2/FP1941 for the detection of homologous recombination on the promoter flank.

Homokaryons for the bcregl deletion strain were obtained by tip isolation and transfer of these tips on CM plates containing nourseothricin at $70 \mu \mathrm{g} / \mathrm{ml}$ (Werner BioAgents, Jena, Germany). Single conidial isolates for the bcregl complementation strain were obtained by spreading a conidial suspension on $\mathrm{CM}$ plates containing hygromycin B at $35 \mu \mathrm{g} / \mathrm{ml}$ (Invitrogen, San Diego, CA, U.S.A.).

\section{Growth assays.}

Stress sensitivity assays were performed by inoculating 3day-old mycelial plugs derived from $\mathrm{CM}$ plates on $\mathrm{CM}$ plates supplemented with 5 or $10 \mathrm{mM} \mathrm{H}_{2} \mathrm{O}_{2}$ (Applichem $\mathrm{GmbH}$, Darmstadt, Germany), $0.8 \mathrm{M}$ sorbitol (Applichem $\mathrm{GmbH}$ ), $0.8 \mathrm{M} \mathrm{NaCl}$ (Merck, Darmstadt, Germany), 0.2\% Calcofluor White (American Cyanamid Company, Princeton, NJ, U.S.A.),

Table 3. Primers used in this study

\begin{tabular}{ll}
\hline Primer & \multicolumn{1}{c}{ Sequence $\left(\mathbf{5}^{\prime}-\mathbf{3}^{\prime}\right)^{\mathbf{a}}$} \\
\hline FP1883 & ccgctcgagttgctacatcatgtgagtcgtg \\
FP1884 & ggccgacgtcgacggtgggtaggttgtgatgtg \\
FP1885 & gctctagagccaagtcagaatccetgttc \\
FP1886 & atagttagcggccgccaaattcaagcctatttaagagctg \\
FP1887 & ataagaatgcggccgcttgctacatcatgtgagtcgtg \\
FP1888 & ggaattccaaattcaagcctatttaagagctg \\
FP1905 & cacatcacaacctacccacc \\
FP1906 & gtcggttcgctagttgattc \\
FP1907 & ggactacctgcgacaagttc \\
FP1939 & agtccaagtcgcatggtagg \\
FP1940 & ttgtgttgataggcgaggtg \\
FP1941 & agtctggaatcggttgatgc \\
Tub-T & agaccagcttgttattgccagtgc \\
pOLI-F1 & acctgcagctctagagccgcattccc \\
FP1942 & ttgatacacacaatgcaaagc \\
Tub-T2 & ggtcctcggagtgcagatggg \\
FP2411 & acacgtcgactccggaaa \\
FP2412 & tctcgatggtacgcttgtca \\
\hline
\end{tabular}

${ }^{a}$ Restriction sites are indicated in bold. 
or $0.2 \%$ Congo red (Sigma) followed by an incubation for 2 days at $18^{\circ} \mathrm{C}$ under light conditions. This growth assay was performed in duplo with two replicates for each condition. A $t$ test was used to determined significant differences. For sclerotia formation, CM plates inoculated with a mycelial plug were incubated at room temperature for 2 weeks in the dark.

\section{Pathogenicity assay.}

Infection of intact and prewounded primary leaves of $P$. vulgaris was performed using agar plugs taken from 3-day-old CM agar plates or using conidiospores isolated from 10- to 14day-old PDA supplemented with $10 \%$ homogenized bean leaves plates as described by Klimpel and associates (2002). Disease symptoms were scored 24 to $168 \mathrm{hpi}$.

\section{Lactophenol Blue staining.}

Infected bean leaves were boiled for $10 \mathrm{~min}$ in a 1:1 mixture of Lactophenol (Sigma-Aldrich) and ethanol, and destained overnight in chloral hydrate at $2.5 \mathrm{~g} / \mathrm{ml}$ (Sigma-Aldrich).

\section{Microscopic analysis of the transformants.}

For SEM analysis of conidia-bearing structures, 4- to 7-mm² pieces were cut from a 1-week-old Gamborg's B5 agar plate supplemented with $2 \%$ glucose previously inoculated with a mycelial plug of B05.10 or of a bcreg1 deletion mutant. For SEM analysis of infected primary $P$. vulgaris leaves, leaves were infected with mycelial plugs of B05.10 or of a bcregl deletion mutant as described above. Lesions were excised from the inoculated leaves 24 hpi. All SEM samples were fixated with aldehyde and dehydrated in an ethanol series as described by Giesbert and associates (1998). Subsequently, the samples were critical point dried (Emitech K850 critical point dryer; Emitech, Ashford, England), gold sputtered (Emitech vacuum sputter device K550x), and examined with a Hitachi S-3000N scanning electron microscope at $15 \mathrm{kV}$.

\section{Southern analysis.}

Fungal genomic DNA was isolated as described by Cenis (1992). The DNA was digested with NcoI, size separated on a $1 \%$ agarose gel, and transferred to a Hybond- $\mathrm{N}^{+}$membrane (Amersham Biosciences, Freiburg, Germany) as described by Sambrook and Russel (2001). Hybridizations were performed overnight in the presence of a random-primed $\left[\alpha{ }^{32} \mathrm{P}\right] \mathrm{dCTP}$ PCR fragment obtained with the primers FP1885/FP1886 corresponding to the bcregl terminator region in a hybridization buffer $(6 \times \mathrm{SSC}[1 \times \mathrm{SSC}$ is $0.15 \mathrm{M} \mathrm{NaCl}$ plus $0.015 \mathrm{M}$ sodium citrate], $5 \times$ Denhardt's solution, $0.1 \%$ sodium dodecyl sulfate [SDS], and $50 \mathrm{mM}$ phosphate buffer, $\mathrm{pH} \mathrm{6.6)} \mathrm{at} 65^{\circ} \mathrm{C}$. Membranes were washed once for $1 \mathrm{~min}$ and once for 5 to $10 \mathrm{~min}$ in $2 \times$ SSPE $(1 \times$ SSPE is $0.18 \mathrm{M} \mathrm{NaCl}, 10 \mathrm{mM} \mathrm{NaPO} 4$, and $1 \mathrm{~nm}$ EDTA [pH 7.7]) and $0.1 \%$ (wt/vol) SDS before being exposed to an autoradiographic film.

\section{Northern analysis.}

Samples for bcregl expression analysis in various $B$. cinerea mutants (Table 2) were obtained by inoculating $100 \mathrm{ml}$ of $1.5 \%$ malt medium (1.5\% malt extract, $2 \%$ glucose, $0.4 \%$ meat peptone, $0.4 \%$ casaminoacids, $0.4 \%$ yeast extract, and $0.08 \%$ ribonucleic acid sodium salt) with mycelium obtained from 3day-old cellophane B5 $+2 \%$ glucose plates. After $24 \mathrm{~h}$ at 150 rpm and $18^{\circ} \mathrm{C}$, mycelium was harvested, washed twice with sterile water, and used to inoculated $100 \mathrm{ml}$ of $\mathrm{CD}$ medium ( $2 \%$ glucose, $0.1 \% \mathrm{NaNO}_{3}, 0.1 \% \mathrm{~K}_{2} \mathrm{HPO}_{4}, 0.05 \% \mathrm{KCl}$, and $0.05 \% \mathrm{MgSO}_{4} \cdot 7 \mathrm{H}_{2} \mathrm{O}, \mathrm{pH} 5.2$ ). Again, after $24 \mathrm{~h}$ at $150 \mathrm{rpm}$ and $18^{\circ} \mathrm{C}$, the mycelium was harvested and washed twice with sterile water, and $3 \mathrm{~g}$ of mycelium was used to inoculate 100 $\mathrm{ml}$ of CD medium. This was performed in duplicate. After 30 min of incubation at $150 \mathrm{rpm}$ and $18^{\circ} \mathrm{C}$, hydrogen peroxide was added to one of the cultures to a final concentration of 10 $\mathrm{mM}$ and incubated for an additional $30 \mathrm{~min}$. Subsequently, the material was harvested and freeze dried overnight. Total RNA was isolated using the Total RNA Isolation System (Promega, Mannheim, Germany) and $20 \mu \mathrm{g}$ of RNA of each sample was transferred to Hybond- $\mathrm{N}^{+}$membrane (Amersham Biosciences) after size separation in a $1 \%$ agarose gel containing formaldehyde as described by Sambrook and Russel (2001). Hybridizations were performed overnight in the presence of a randomprimed $\left[\alpha-{ }^{32} \mathrm{P}\right] \mathrm{dCTP} 478-\mathrm{bp}$ PCR fragment corresponding to a part of the bcregl ORF in a hybridization buffer $(0.6 \mathrm{M} \mathrm{NaCl}$, $0.16 \mathrm{M} \mathrm{Na}_{2} \mathrm{HPO}_{4}, 0.06 \mathrm{M}$ EDTA, $1 \% \mathrm{~N}$-lauroylsarcosine [Sigma-Aldrich], 10\% dextran sulfate [Eppendorf AG, Hamburg, Germany], and $0.01 \%$ salmon sperm DNA, pH 6.2), at $65^{\circ} \mathrm{C}$. Membranes were washed 5 to $10 \mathrm{~min}$ in $2 \times$ SSPE and $0.1 \%$ (wt/vol) SDS before being exposed to an autoradiographic film.

\section{Analysis of metabolite production.}

For analysis of metabolite production, the wild type and the bcreg1 deletion mutants were grown on malt agar medium, (Dglucose at $20 \mathrm{~g} /$ liter, malt extract at $10 \mathrm{~g} / \mathrm{liter}$, agar at $20 \mathrm{~g} / \mathrm{liter}$, and peptone at $1 \mathrm{~g} / \mathrm{liter}, \mathrm{pH} 6.5$ to 7 ) at $25^{\circ} \mathrm{C}$ and used to inoculate petri discs with solid malt agar on which all studied strains were fermented. Petri plates $(n=20)$ were inoculated with three small plugs of agar $(1 \mathrm{~cm})$ with mycelium of $B$. cinerea per disk and incubated for 15 days. Then the solid agar malt medium was cleaned from mycelia and conidia and separately extracted with ethyl acetate $(3 \times 0.5 \mathrm{vol})$ using an ultrasonic bath $(15 \mathrm{~min})$. The organic extracts were dried over $\mathrm{Na}_{2} \mathrm{SO}_{4}$ and concentrated to dryness.

${ }^{1} \mathrm{H}$ - and ${ }^{13} \mathrm{C}-\mathrm{NMR}$ measurements on metabolites isolated from culture extracts were obtained on Varian Unity 400 and Varian Innova $600 \mathrm{NMR}$ spectrometers with $\mathrm{SiMe}_{4}$ as the internal reference. Mass spectra were recorded on a gas chromatography-mass spectrometry (GC-MS) Thermoquest Voyager spectrometer and a VG Autospec-Q spectrometer. Highperformance liquid chromatography (HPLC) was performed with a Hitachi/Merck L-6270 apparatus equipped with a UVVIS detector (L 6200) and a differential refractometer detector (RI-71). Thin-layer chromatography was performed on Merck Kiesegel $60 \mathrm{~F}_{254}, 0.2 \mathrm{~mm}$ thick. Silica gel (Merck) was used for column chromatography. HPLC purification was accomplished with a silica gel column (Hibar 60: $7 \mathrm{~m}, 1 \mathrm{~cm}$ wide, 25 $\mathrm{cm}$ long). Chemicals were products of Fluka or Sigma-Aldrich. All solvents were freshly distilled.

For isolation and characterization of metabolites, the oil extract obtained from extraction of the solid malt agar medium were separated by means of column chromatography on silica gel, with a mixture of ethyl acetate/hexane $(10,20,40,60,80$ and $100 \%$ ethyl acetate) and $20 \%$ methanol in ethyl acetate as solvent. The extract obtained from mycelium yielded an intractable mixture of fatty acids.

Extensive spectroscopic analysis by ${ }^{1} \mathrm{H}-\mathrm{NMR}$ and ${ }^{13} \mathrm{C}-\mathrm{NMR}$ were used to detect the presence of the various toxins in each fraction. Candidate fractions were further purified by HPLC with an increasing gradient of ethyl acetate to petroleum ether. The toxin structures were analyzed by spectroscopic methods and direct comparison with authentic samples, previously isolated from strains of B. cinerea (Collado et al. 2000).

\section{ACKNOWLEDGMENTS}

We thank M. Hahn for providing the bmpl and bpm3 deletion mutants; B. Tudzynski for providing the pka1, pka2, pkaR, and bac deletion mutants; J. van Kan for performing the sexual crossing experiments; B. Richter 
for technical assistance; and the Deutsche Forschungsgemeinschaft (DFG, Tu 50/15-2) and the Ministerio de Ciencia e Innovación (MICINN) AGL2009-13359-C02-01, Spain) for financial support. C. B. Michielse was funded by fellowships of the European Molecular Biology Organization (EMBO, ASTF 308.00-2007), the Federation of European Microbiological Societies (FEMS), and the German Academic Exchange Service (DAAD, 312:A/08/10374).

\section{LITERATURE CITED}

Adams, T. H., Hide, W. A., Yager, L. N., and Lee, B. N. 1992. Isolation of a gene required for programmed initiation of development by Aspergillus nidulans. Mol. Cell. Biol. 12:3827-3833.

Adams, T. H., Wieser, J. K., and Yu, J. H. 1998. Asexual sporulation in Aspergillus nidulans. Microbiol. Mol. Biol. Rev. 62:35-54.

Bishop, C. D., and Cooper, R. M. 1983. An ultrastructural study of root invasion in three vascular wilt diseases. Physiol. Plant Pathol. 22:15.

Caspari, T. 1997. Onset of gluconate-H+ symport in Schizosaccharomyces pombe is regulated by the kinases Wis 1 and Pka1, and requires the gti1+ gene product. J. Cell Sci. 110:2599-2608.

Cenis, J. 1992. Rapid extraction of fungal DNA for PCR amplification. Nucleic Acids Res. 20:2380.

Choquer, M., Fournier, E., Kunz, C., Levis, C., Pradier, J. M., Simon, A., and Viaud, M. 2007. Botrytis cinerea virulence factors: New insights into a necrotrophic and polyphagous pathogen. FEMS (Fed. Eur. Microbiol. Soc.) Microbiol. Lett. 277:1-10.

Clutterbuck, A. J. 1969. A mutational analysis of conidial development in Aspergillus nidulans. Genetics 63:317-327.

Collado, I. G., Aleu, J., Hernandez-Galan, R., and Duran-Patron, R. 2000. Botrytis species: An intriguing source of metabolites with wide ranges of biological activities. Structure, chemistry and bioactivity of metabolites isolated from Botrytis species. Curr. Org. Chem. 4:1261-1286.

Collado, I. G., Sanchez, A. J., and Hanson, J. R. 2007. Fungal terpene metabolites: Biosynthetic relationships and the control of the phytopathogenic fungus Botrytis cinerea. Nat. Prod. Rep. 24:674-686.

Colmenares, A. J., Aleu, J., Duran-Patron, R., Collado, I. G., and HernandezGalan, R. 2002. The putative role of botrydial and related metabolites in the infection mechanism of Botrytis cinerea. J. Chem. Ecol. 28:9971005.

Doehlemann, G., Berndt, P., and Hahn, M. 2006. Different signalling pathways involving a $\mathrm{G}$ alpha protein, cAMP and a MAP kinase control germination of Botrytis cinerea conidia. Mol. Microbiol. 59:821-835.

Eisman, B., Alonso-Monge, R., Roman, E., Arana, D., Nombela, C., and Pla, J. 2006. The Cek1 and Hog1 mitogen-activated protein kinases play complementary roles in cell wall biogenesis and chlamydospore formation in the fungal pathogen Candida albicans. Eukaryot. Cell 5:347-358.

Fernandez-Acero, F. J., Jorge, I., Calvo, E., Vallejo, I., Carbu, M., Camafeita, E., Garrido, C., Lopez, J. A., Jorrin, J., and Cantoral, J. M. 2007. Proteomic analysis of phytopathogenic fungus Botrytis cinerea as a potential tool for identifying pathogenicity factors, therapeutic targets and for basic research. Arch. Microbiol. 187:207-215.

Giesbert, S., Lepping, H. B., Tenberge, K. B., and Tudzynski, P. 1998. The xylanolytic system of Claviceps purpurea: Cytological evidence for secretion of xylanases in infected rye tissue and molecular characterization of two xylanase genes. Phytopathology 88:1020-1030.

Gioti, A., Simon, A., Le Pecheur, P., Giraud, C., Pradier, J. M., Viaud, M., and Levis, C. 2006. Expression profiling of Botrytis cinerea genes identifies three patterns of up-regulation in planta and an FKBP12 protein affecting pathogenicity. J. Mol. Biol. 358:372-386.

Govrin, E.M., and Levine, A. 2000. The hypersensitive response facilitates plant infection by the necrotrophic pathogen Botrytis cinerea. Curr. Biol. 10:751-757.

Huang, G., Wang, H., Chou, S., Nie, X., Chen, J., and Liu, H. 2006. Bistable expression of WOR1, a master regulator of white-opaque switching in Candida albicans. Proc. Natl. Acad. Sci. U.S.A. 103:12813-12818.

Huang, G., Yi, S., Sahni, N., Daniels, K. J., Srikantha, T., and Soll, D. R. 2010. N-acetylglucosamine induces white to opaque switching, a mating prerequisite in Candida albicans. PLoS Pathog. 6:e1000806. Published online.

Kars, I., Krooshof, G. H., Wagemakers, L., Joosten, R., Benen, J. A., and van Kan, J. A. 2005. Necrotizing activity of five Botrytis cinerea endopolygalacturonases produced in Pichia pastoris. Plant J. 43:213-225.

Kim, K. S., Min, J. Y., and Dickman, M. B. 2008. Oxalic acid is an elicitor of plant programmed cell death during Sclerotinia sclerotiorum disease development. Mol. Plant-Microbe Interact. 21:605-612.

Klimpel, A., Schulze-Gronover, C., Williamson, B., Stewart, J., and Tudzynski, B. 2002. The adenylate cyclase (BAC) in Botrytis cinerea is required for full pathogenicity. Mol. Plant. Pathol. 3:439-450.
Koch, E., and Slusarenko, A. 1990. Arabidopsis is susceptible to infection by a downy mildew fungus. Plant Cell 2:437-445.

Lagopodi, A. L., Ram, A. F., Lamers, G. E., Punt, P. J., Van den Hondel, C. A., Lugtenberg, B. J., and Bloemberg, G. V. 2002. Novel aspects of tomato root colonization and infection by Fusarium oxysporum f. sp. radicis-lycopersici revealed by confocal laser scanning microscopic analysis using the green fluorescent protein as a marker. Mol. PlantMicrobe Interact. 15:172-179.

Lohse, M. B., Zordan, R. E., Cain, C. W., and Johnson, A. D. 2010. Distinct class of DNA-binding domains is exemplified by a master regulator of phenotypic switching in Candida albicans. Proc. Natl. Acad. Sci. U.S.A. 107:14105-14110.

Malonek, S., Rojas, M. C., Hedden, P., Gaskin, P., Hopkins, P., and Tudzynski, B. 2004. The NADPH-cytochrome P450 reductase gene from Gibberella fujikuroi is essential for gibberellin biosynthesis. J. Biol. Chem. 279:25075-25084.

Michielse, C. B., van Wijk, R., Reijnen, L., Manders, E. M., Boas, S., Olivain, C., Alabouvette, C., and Rep, M. 2009. The nuclear protein Sge1 of Fusarium oxysporum is required for parasitic growth. PLoS Pathog. 5:e1000637. Published online.

Nguyen, V. Q., and Sil, A. 2008. Temperature-induced switch to the pathogenic yeast form of Histoplasma capsulatum requires Ryp1, a conserved transcriptional regulator. Proc. Natl. Acad. Sci. U.S.A. 105:4880-4885.

O'Rourke, S. M., and Herskowitz, I. 1998. The Hog1 MAPK prevents cross talk between the HOG and pheromone response MAPK pathways in Saccharomyces cerevisiae. Genes Dev. 12:2874-2886.

Pontecorvo, G., Roper, J., Hummonns, L., MacDonald, K., and Buften, A. 1953. The genetics of Aspergillus nidulans. Adv. Genet. 141:141-238.

Prins, T., Wagemakers, L., Schouten, A., and van Kan, J. 2000a. Cloning and characterization of a glutathion- $S$-transferase homologue from the plant pathogen Botrytis cinerea. Mol. Plant. Pathol. 1:169-178.

Prins, T., Wagemakers, L., and Van Kan, J. 2000b. Structure and expression in planta of Botrytis cinerea ubiquitin genes. Eur. J. Plant Pathol 106:693-698.

Quidde, T., Büttner, P., and Tudzynski, P. 1999. Evidence for three different specific spaonin-detoxifying activities in Botrytis cinerea and cloning and functional analysis of a gene coding for a putative aveacinase. Eur. J. Plant Pathol. 105:273-283.

Reino, J. L., Hernandez-Galan, R., Duran-Patron, R., and Collado, I. G. 2004. Virulence-toxin production relationship in isolates of the plant pathogenic fungus Botrytis cinerea. J. Phytopathol. 152:563-566.

Rodriguez-Galvez, E., and Mendgen, K. 1995. Cell wall synthesis in cotton roots after infection with Fusarium oxysporum. The deposition of callose, arabinogalactans, xyloglucans, and pectic components into walls, wall appositions, cell plates and plasmodesmata. Planta 197:535545.

Rolke, Y., Liu, S., Quidde, T., Williamson, B., Schouten, S., Weltring, K.M., Sievers, V., Tudzynski, B., and Tudzynski, P. 2004. Functional analysis of $\mathrm{H}_{2} \mathrm{O}_{2}$-generating systems in Botrytis cinerea: The major $\mathrm{Cu}$ $\mathrm{Zn}$-superoxide dismutase (BcSOD1) contributes to virulence on French bean, whereas a glucose oxidase (BcGOD1) is dispensable. Mol. Plant. Pathol. 5:17-27.

Rui, O., and Hahn, M. 2007. The Slt2-type MAP kinase Bmp3 of Botrytis cinerea is required for the normal saprotrophic growth, conidiation, plant surface sensing and host tissue colonization. Mol. Plant. Pathol. 8:173-184.

Sambrook, J., and Russel, D. 2001. Molecular Cloning: A Laboratory Manual. Cold Spring Harbor Laboratory Press, Cold Spring Harbor, NY, U.S.A.

Schamber, A., Leroch, M., Diwo, J., Mendgen, K., and Hahn, M. 2010 The role of mitogen-activated protein (MAP) kinase signalling components and the Ste 12 transcription factor in germination and pathogenicity of Botrytis cinerea. Mol. Plant Pathol. 11:105-119.

Schouten, A., Tenberge, K., Vermeer, J., Stewart, J., Wagemakers, L., Williamson, B., and van Kan, J. 2002. Functional analysis of an extracellular catalase of Botrytis cinerea. Mol. Plant. Pathol. 3:227-238.

Schouten, A., van Baarlen, P., and van Kan, J. A. 2008. Phytotoxic Nep1like proteins from the necrotrophic fungus Botrytis cinerea associate with membranes and the nucleus of plant cells. New Phytol. 177:493505.

Schulze-Gronover, C., Kasulke, D., Tudzynski, P., and Tudzynski, B. 2001. The role of $G$ protein alpha subunits in the infection process of the gray mold fungus Botrytis cinerea. Mol. Plant-Microbe Interact. 14:1293-1302.

Schulze-Gronover, C., Schorn, C., and Tudzynski, B. 2004. Identification of Botrytis cinerea genes up-regulated during infection and controlled by the $\mathrm{G}$ alpha subunit BCG1 using suppression subtractive hybridization (SSH). Mol. Plant-Microbe Interact. 17:537-546.

Schumacher, J., de Larrinoa, I. F., and Tudzynski, B. 2008a. Calcineurin- 
responsive zinc finger transcription factor CRZ1 of Botrytis cinerea is required for growth, development, and full virulence on bean plants. Eukaryot. Cell 7:584-601.

Schumacher, J., Kokkelink, L., Huesmann, C., Jimenez-Teja, D., Collado, I., Barakat, R., Tudzynski, P., and Tudzynski, B. 2008b. The cAMPdependent signaling pathway and its role in conidial germination, growth, and virulence of the gray mold Botrytis cinerea. Mol. Plant-Microbe Interact. 21:1443-1459.

Segmüller, N., Ellendorf, U., Tudzynski, B., and Tudzynski, P. 2007. $\mathrm{BcSAK} 1$, a stress-activated mitogen-activated protein kinase, is involved in vegetative differentiation and pathogenicity in Botrytis cinerea. Eukaryot. Cell 6:211-221.

Segmuller, N., Kokkelink, L., Giesbert, S., Odinius, D., van Kan, J., and Tudzynski, P. 2008. NADPH oxidases are involved in differentiation and pathogenicity in Botrytis cinerea. Mol. Plant-Microbe Interact. 21:808-819.

Shah, P., Atwood, J. A., Orlando, R., El Mubarek, H., Podila, G. K., and Davis, M. R. 2009. Comparative proteomic analysis of Botrytis cinerea secretome. J. Proteome Res. 8:1123-1130.

Siewers, V., Viaud, M., Jimenez-Teja, D., Collado, I. G., Gronover, C. S., Pradier, J. M., Tudzynski, B., and Tudzynski, P. 2005. Functional analysis of the cytochrome P450 monooxygenase gene bcbot 1 of Botrytis cinerea indicates that botrydial is a strain-specific virulence factor. Mol Plant-Microbe Interact. 18:602-612.

Srikantha, T., Borneman, A. R., Daniels, K. J., Pujol, C., Wu, W., Seringhaus, M. R., Gerstein, M., Yi, S., Snyder, M., and Soll, D. R. 2006. TOS9 regulates white-opaque switching in Candida albicans. Eukaryot. Cell 5:1674-1687.

Tani, H., Koshino, H., Sakuno, E., Cutler, H. G., and Nakajima, H. 2006. Botcinins $\mathrm{E}$ and $\mathrm{F}$ and Botcinolide from Botrytis cinerea and structural revision of botcinolides. J. Nat. Prod. 69:722-725.

Temme, N., and Tudzynski, P. 2009. Does Botrytis cinerea ignore $\mathrm{H}_{2} \mathrm{O}_{2}$ induced oxidative stress during infection? Characterization of Botrytis activator protein 1. Mol. Plant-Microbe Interact. 22:987-998.

Tenberge, K. B., Beckedorf, M., Hoppe, B., Schouten, A., Solf, M., and von den Driesch, M. 2002. In situ localization of AOS in host-pathogen interactions. Microsc. Microanal. 8:250-251.

Ten Have, A., Mulder, W., Visser, J., and van Kan, J. 1998. The endopolygalacturonase gene Bcpg1 is required for full virulence of Botrytis cinerea. Mol. Plant-Microbe Interact. 11:1009-1016.

Tudzynski, P., and Kokkelink, L. 2009. Botrytis cinerea: Molecular aspects of a necrotrophic life-style. Pages 29-50 in: The Mykota. N. S. Iacobellis, A. Collmer, S. W. Hutcheson, J. W. Mansfield, C. E. Morris, J. Murillo, N. W. Schaad, D. E. Stead, G. Surico, and M. Ullrich, eds. Kluwer Academic Springer, Dordrecht, The Netherlands.

Van Kan, J. A. 2006. Licensed to kill: The lifestyle of a necrotrophic plant pathogen. Trends Plant Sci. 11:247-253.

Williamson, B., Tudzynski, B., Tudzynski, P., and van Kan, J. A. 2007. Botrytis cinerea: The cause of grey mould disease. Mol. Plant Pathol. 8:561-580.

Yamashiro, C. T., Ebbole, D. J., Lee, B. U., Brown, R. E., Bourland, C., Madi, L., and Yanofsky, C. 1996. Characterization of rco-1 of Neurospora crassa, a pleiotropic gene affecting growth and development that encodes a homolog of Tup1 of Saccharomyces cerevisiae. Mol. Cell. Biol. 16:6218-6228.

Zordan, R. E., Galgoczy, D. J., and Johnson, A. D. 2006. Epigenetic properties of white-opaque switching in Candida albicans are based on a self-sustaining transcriptional feedback loop. Proc. Natl. Acad. Sci. U.S.A. 103:12807-12812.

\section{AUTHOR-RECOMMENDED INTERNET RESOURCES}

Pathogen-Host Interactions database (PHIbase): www.phibase.org Broad Institution's Botrytis. cinerea genome sequence database: www.broad.mit.edu/annotation/genome/botrytis_cinerea/home.html 